\title{
Interdisciplinary Collaboration: Librarian Involvement in Grant Projects
}

\author{
Marci D. Brandenburg, Sigrid Anderson Cordell, Justin \\ Joque, Mark P. MacEachern, and Jean Song*
}

\begin{abstract}
Librarians are excellent research collaborators, although librarian participation is not usually considered, thereby making access to research funds difficult. The University of Michigan Library became involved in the university's novel funding program, MCubed, which supported innovative interdisciplinary research on campus, primarily by funding student assistants to work on research projects. This article discusses three different MCubed projects that all benefited from librarian involvement. These projects spanned across many areas from translational research to systematic reviews to digital humanities. Librarian roles ranged from mentoring and project management to literature searching.
\end{abstract}

\section{Introduction}

Traditionally, librarians have adopted supportive roles in their research collaborations with faculty. While such roles still exist within academic librarianship, there is an increasing emphasis on librarians as partners within research collaborations. ${ }^{1}$ These partnerships include grants, systematic review publications (a specific type of comprehensive literature review), and other projects that benefit from librarians' specialized skillsets. The ability to contribute funds to a research collaboration creates a more balanced partnership, allowing librarians to more fully contribute to projects with other faculty researchers. The University of Michigan (UM) University Library values collaboration and participation in research, which is evident through the library's participation in the MCubed program, a recent pilot program designed to fund innovative interdisciplinary research on campus. The University Library participated in the program, providing an opportunity for the authors of this paper to propose projects, find interdisciplinary collaborators, and contribute funding to conduct research. Most important, because librarians were equal contributors of funding, they engaged in these

\footnotetext{
${ }^{*}$ Marci D. Brandenburg is Bioinformationist in the Taubman Health Sciences Library, Department of Computational Medicine E Bioinformatics, and Bioinformatics Core at the University of Michigan; e-mail: mbradenb@umich.edu. Sigrid Anderson Cordell is Librarian for English Language and Literature and Justin Joque is Visualization Librarian in the Hatcher Graduate Library at the University of Michigan; e-mail: scordell@umich.edu, joque@umich.edu. Mark P. MacEachern is Informationist and Jean Song is Assistant Director, Research and Informatics in the Taubman Health Sciences Library at the University of Michigan; e-mail: markmac@umich.edu, jeansong@umich.edu. (C2017 Marci D. Brandenburg, Sigrid Anderson Cordell, Justin Joque, Mark P. MacEachern, and Jean Song, Attribution-NonCommercial (http:// creativecommons.org/licenses/by-nc/4.0/) CC BY-NC.
} 
projects as full collaborators, paving the way for stronger relationships with faculty and future research opportunities.

The inability to obtain funding is a common barrier to librarian involvement in research initiatives. In 2009, Gore et al., after discovering that a only a quarter of research articles published in top health sciences library journals identified funding sources, noted that "funding for health sciences library research remains either limited or nonexistent." 2 Yet, at the same time, funding is perceived by Association of Research Libraries (ARL) library directors to be one of the most effective mechanisms for promoting research among librarians. ${ }^{3}$ Further, there is evidence to suggest that funded research is associated with "substantially higher impact" than nonfunded research. ${ }^{4}$ Not only did participation in the MCubed program provide librarians with funding opportunities, it also set the stage for meaningful collaborations with nonlibrary faculty across campus, which is generally underreported in the literature. ${ }^{5}$

This paper outlines three interdisciplinary research projects that originated from a unique funding situation that came about at the University of Michigan. The projects are diverse, involving librarians from the humanities and health sciences, covering digital literary texts, bioinformatics tools, and evidence from the literature to inform medical decisions. Furthermore, the extent to which the librarians were involved in the projects, and the range of responsibilities they took on, suggest to others possibilities for involvement and collaboration in research projects. These projects are examples of contributions to research that redefine librarian roles and help rewrite librarian stereotypes. The projects are examples of successful interdisciplinary collaborations that help fill a gap in the library literature and emphasize the impact librarians have on research when they are made equal partners through funding.

\section{Background}

In 2012, the University of Michigan piloted the MCubed program, which supported innovative, faculty-proposed interdisciplinary research on campus, primarily by funding student assistants to work on research projects. In this way, the program had a strong undergraduate and graduate education component. Project proposals had to enlist the support of three faculty members to form a "cube," with at least two different unit affiliations represented. One goal of MCubed was to provide quick funding for projects; as a result, there was no peer-review process, but it was believed that the requirement to have three faculty from different units provided a level of review, in itself. Proposals that met the criteria of having the support of three faculty from at least two different departments were then funded at $\$ 60,000$ by a random selection process handled by the UM's Office of Research. This selection process was necessary since more proposals were submitted than could be funded. A majority of the awarded funds had to be allocated specifically to student salaries. The funding period was two years, and unused funds were returned to the funding groups. The funding for this program came from a combination of the UM's Provost's Office, UM's Rackham Graduate School, and all participating UM schools/colleges and their faculty. In total, 222 "cubes" were funded. ${ }^{6}$

When the MCubed program was started, librarians were not originally included as faculty contributors in the program and were, in fact, overlooked as potential research partners. This oversight was consistent with the view of librarians as part of a support system rather than as collaborators with equal standing among other faculty. It was only after the MCubed program had been announced and marketed to departments, and a faculty member in English sought a library collaborator, that the idea of including librarians came under consideration. From the library's point of view, however, collaborating with faculty researchers was a natural outgrowth of its mission, and 
the Dean of Libraries agreed to fully fund four librarians at $\$ 20,000$ each, for a total contribution of $\$ 80,000$ to the grant funding process.

\section{The Cubing Process}

Each independent investigator in the program, as defined by his or her unit, received one "token." Each token represented \$20,000 to contribute to a cube. The University Library funded four tokens. Three tokens from two different units had to be redeemed on a project to form a "cube" (see figure 1). A total of 85 percent of the funds had to be used to support undergraduate students, graduate students, or postdocs. Successful cubes were funded in total of $\$ 60,000$ by a random selection process. While any investigator who belonged to a department that participated in the MCubed program could submit cube proposals, the departments allocated a specific budget amount and therefore could only fund a specified number of tokens, limiting the number of cubes that could be funded. All cubes that successfully met the criteria of the program (three faculty from at least two departments) were entered into a pool from which cubes were randomly selected to be funded. Any cube had a similar chance of being selected from this pool.

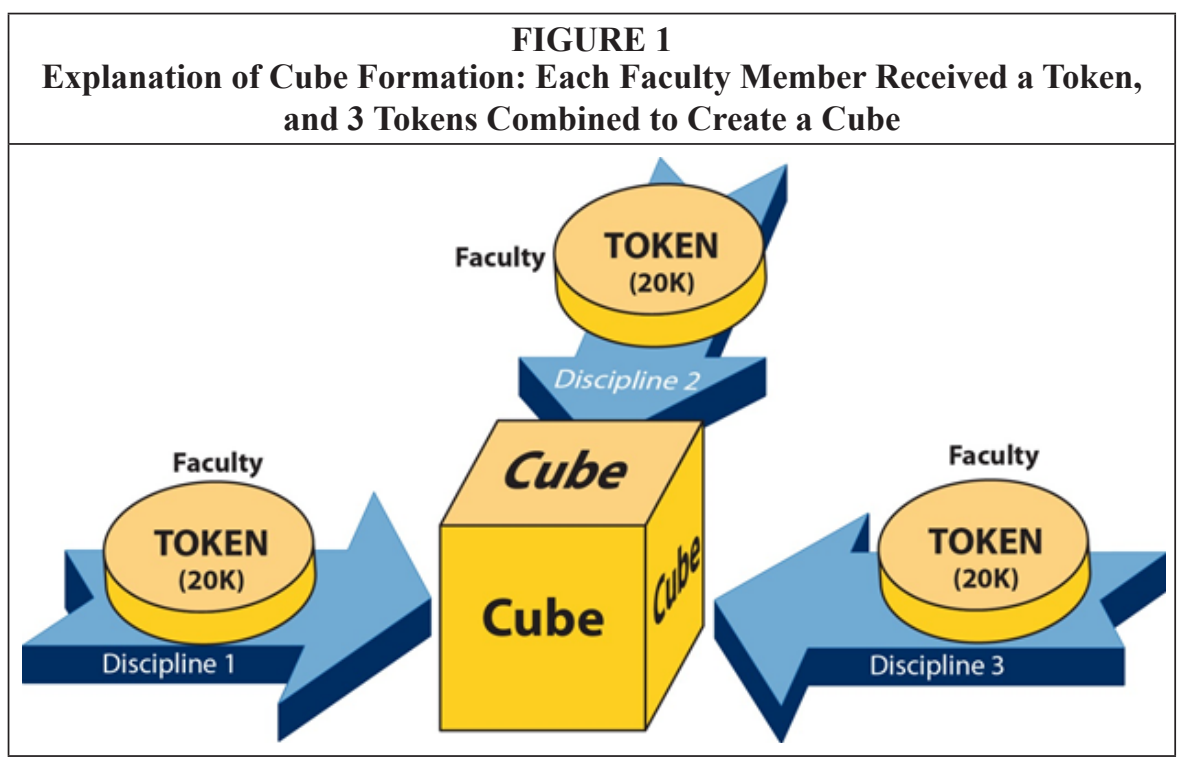

\section{The Projects}

Given the maximum number of tokens that each participating UM unit chose to fund, there were 1,057 fundable tokens available for projects, meaning that 352 cubes could conceivably have been funded, as each project required three tokens. Successful funding, however, required not only the formation of a cube with three tokens, but also that the cube be chosen during the random selection process. If a cube was not chosen, the cube dissolved and no funding was received. All 154 faculty within the UM University Library had the opportunity to contribute a token to, or create, a project, and all four of the tokens the library agreed to fund were successfully used in cubes. ${ }^{7}$ Once four library tokens were funded, no more cubes containing a library token could receive funding. As a result, not all submitted cubes that contained a library token received 
funding. One funded cube included two librarians, therefore using two library tokens; as a result, three cubes that included a total of four library tokens received funding through this program. The three funded cubes were: 1) Scientific Needs Assessment and Analysis of Bioinformatics Tools to Support Clinical and Translational Research; 2) Core Outcomes Measures for Rotator Cuff Disorders; and 3) Using the Digital to Read Literary Texts in Context. The following sections describe these fully funded projects and discuss the multiple ways in which librarians contributed to the research enterprise (see table 1).

\begin{tabular}{|l|l|l|l|}
\hline \multicolumn{4}{|c|}{$\begin{array}{l}\text { TABLE 1 } \\
\text { Comparison of } 3 \text { Interdisciplinary Projects, Including the Role } \\
\text { and Significance of Librarian Involvement and the Work Accomplished } \\
\text { for each Project }\end{array}$} \\
\hline & $\begin{array}{l}\text { Scientific Needs } \\
\text { Assessment } \\
\text { and Analysis of } \\
\text { Bioinformatics } \\
\text { Tools to Support } \\
\text { Clinical \& } \\
\text { Translational } \\
\text { Research }\end{array}$ & $\begin{array}{l}\text { Core Outcomes } \\
\text { Measures for } \\
\text { Rotator Cuff } \\
\text { Disorders }\end{array}$ & $\begin{array}{l}\text { Using the Digital } \\
\text { to Read Literary } \\
\text { Texts in Context }\end{array}$ \\
\hline Librarian Role & $\begin{array}{l}\text { Project management } \\
\text { and mentorship }\end{array}$ & Literature searching & $\begin{array}{l}\text { Project management } \\
\text { and mentorship }\end{array}$ \\
\hline $\begin{array}{l}\text { Work } \\
\text { Accomplished }\end{array}$ & $\begin{array}{l}\text { Bioinformatics } \\
\text { tools assessment } \\
\text { and creation of } \\
\text { instruction resources }\end{array}$ & $\begin{array}{l}\text { Analysis of rotator } \\
\text { cuff studies in } \\
\text { literature }\end{array}$ & $\begin{array}{l}\text { Data collection of } \\
\text { specific periodicals }\end{array}$ \\
\hline $\begin{array}{l}\text { Librarian } \\
\text { Significance }\end{array}$ & $\begin{array}{l}\text { Positive student } \\
\text { experience, } \\
\text { creation of project } \\
\text { deliverables }\end{array}$ & $\begin{array}{l}\text { Highly skilled } \\
\text { literature search }\end{array}$ & $\begin{array}{l}\text { Positive student } \\
\text { experience, } \\
\text { development } \\
\text { of transferrable } \\
\text { data collection } \\
\text { methodologies }\end{array}$ \\
\hline
\end{tabular}

\section{Scientific Needs Assessment and Analysis of Bioinformatics Tools to Support Clinical and Translational Research}

This cube consisted of one library token, from the Taubman Health Sciences Library's (THL) Assistant Director for Research and Informatics, and two medical school tokens, representing Internal Medicine and the Department of Computational Medicine \& Bioinformatics (DCM\&B). Additional faculty and staff from the library and DCM\&B were nontoken collaborators on this project, meaning that they worked on this project but did not contribute funds.

\section{Cube Discovery Process}

This project was one of three related cubes that were created with help from the Director of Informatics Infrastructure in DCM\&B and the Bioinformationist, a bioinformatics librarian specialist in THL. The Bioinformationist originally proposed the idea of creating a cube based on tranSMART and helped find faculty to participate in the process. 
tranSMART is an open source data sharing and analysis platform for furthering translational research developed through a public-private partnership that includes academic institutions, commercial entities, and nonprofit organizations. ${ }^{8}$ The Bioinformationist, along with DCM\&B's Director of Informatics Infrastructure, identified areas within the tranSMART project that lacked personnel for development and could be filled with student effort as specified by the cube requirements. These areas included computer programming for data loading purposes, heuristic analyses of workflows and bioinformatics tools, and training material development. After discussions with interested faculty from THL, DCM\&B, Internal Medicine, and other units, three distinct projects were proposed, meaning nine faculty were involved, including two from the library. Unfortunately, only one of the two projects with librarian involvement was funded. The other cube received no funds, and the project did not move forward.

\section{Librarian Role in Cube}

Despite not being the named librarian collaborator on this cube, the THL Bioinformationist was extensively involved in this cube project with support from the THL Assistant Director for Research and Informatics, who was the official librarian collaborator. The latter librarian worked with finance to get regular updates on the project budget, while the Bioinformationist took on the project management role, in addition to her previous work as project developer that had led to the three original funding proposals, facilitated communication between all stakeholders, and ensured that the project moved forward. Seven students were hired to work on this cube, most of whom were attending UM's School of Information. The Bioinformationist led the student recruitment effort by writing many of the job descriptions, conducting student interviews, and selecting the successful candidates. She was also the primary supervisor and mentor for four of the students. As such, she worked to ensure that the students had positive educational experiences, while accomplishing the tasks requested of them. They remained busy and were challenged, yet also received appropriate mentorship to help them achieve the desired end results. The Bioinformationist and the students often met weekly to discuss their projects and the plan for the upcoming week. Confirmation of task completion and designing new short-term goals was necessary to keep the project moving forward, and these roles fell under the purview of the Bioinformationist. In addition, she was the connector between the students and other faculty and staff invested in the work, including programmers working on the tranSMART code.

\section{Work Accomplished from Funding}

The MCubed students accomplished several different projects for the tranSMART work. Under the project management and mentorship of the Bioinformationist, two students conducted an assessment of locally developed bioinformatics tools. This included a literature review for similar resources and a citation analysis for the locally developed tools. The students conducted heuristic evaluations of the tools and developed prototypes of these tools integrated into the tranSMART platform. Also under the mentorship of the Bioinformationist, two additional students created instructional resources that included numerous video tutorials for using tranSMART. The Bioinformationist provided feedback on drafts of student-created tutorials and ensured the video topics met the stakeholders' needs. The video tutorials, which included closed captioning, were made freely available on the tranSMART Foundation's YouTube Channel. ${ }^{9}$ Since no instructional materials existed for helping users load data into tranSMART, a written manual was created stepping users through the data loading process, in addition to a video tutorial, filling this need. In addition, a hands-on training session, "Introduction 
to tranSMART," was offered at the University of Michigan. This training session was cotaught by one of the MCubed-funded students and the Bioinformationist. With help from the Bioinformationist and the Assistant Director of Research and Informatics, students displayed their work as a poster at each of the MCubed Annual Symposiums, giving them real-world presentation experience.

\section{Librarian Participation Significance}

MCubed provided an opportunity for librarians to demonstrate the value of the partnership between librarians and medical school faculty. The librarians provided grant funding, project management leadership, and student mentorship. The tranSMART instruction materials were highly valued by faculty in DCM\&B and by members of the tranSMART Foundation, as they were important resources that furthered the adoption of the tranSMART platform. Without librarian-initiated grant proposals and project management, this work would not have been accomplished. This project also provided important educational opportunities and real-world work experience for students. One student commented, "In the particular project I worked on, I was able to view the bioinformatics field from a unique angle that allowed me to not only learn about the field itself, but also about creating informative material that can benefit others." This cube project reinforced the value of librarians as strong grant partners, project leaders, and student mentors in the funded research environment.

\section{Core Outcomes Measures for Rotator Cuff Disorders Cube Discovery Process}

This project was initially conceived of and put forward by a faculty member in the UM School of Public Health. The project consisted of a systematic review, which is a comprehensive literature review that aims to objectively identify, synthesize, and summarize all relevant evidence on a research topic. Because well-constructed systematic reviews adhere to a stringent set of methodological standards and processes, the resulting publications tend to have significant influence on health policies and clinical decisions. The THL librarian, known as an "Informationist" in the health sciences schools, who became involved in this MCubed project identified the opportunity by proactively seeking systematic review proposals on the MCubed website. ${ }^{10}$ Upon discovering the proposal, he reached out to the project lead, with whom he had worked previously on projects, and offered to contribute his search expertise and his token to cube the project.

\section{Librarian Role in Cube}

The Informationist conducted a comprehensive literature search in PubMed, one of the largest biomedical literature databases, and other resources to identify studies on patient-reported and physician-assessed outcome measures for rotator cuff conditions. Systematic reviews (SR) differ from other types of reviews because of their rigorous methodology that is in place to reduce subjectivity and bias from all aspects of the review and its analyses. The standards that govern SR methods extend to the search process, and it behooves the searcher(s) and benefits the project to adhere to the search-related standards closely. Failure to adhere to the standards or failure to report on essential aspects of the search in the SR manuscript as outlined in the standards can result in poor results and rejected manuscripts. In practical terms, the SR search process includes complex search strategies designed to capture all published and unpublished literature on the research question, which means that specialized knowledge of the resources is essential and that constructing and documenting the search process takes significant time. The searches in this project resulted in most of 
the data that formed the backbone of the analysis. The Informationist documented the searches, kept track of search results and duplicate records, and worked with research assistants on citation management.

As a side project, the Informationist assessed the validity of a published PubMed search filter that was created to capture studies pertaining to patient-reported outcome measures. To do so, the Informationist created a pool of the approximately 100 citations involving outcome measures the team identified through full-text review, and sought to determine how well the published filter captured the pool of citations known to be relevant. The Informationist then applied the filter to a PubMed search that he created to capture all studies pertaining to rotator cuff conditions. The idea was that if the team created a search that was sensitive enough to capture most rotator cuff papers, then the patient-reported outcome filter could be applied to that search to quickly isolate those rotator cuff studies of interest to the project. In addition to developing the literature searches that supported the analysis, the Informationist contributed to discussions about the project plan when appropriate. The other two members of the team, including the project lead, were epidemiologists with extensive experience designing and conducting systematic reviews; they handled most methodological and clinical considerations.

\section{Work Accomplished from Funding}

Using cube funds, students were hired as research assistants to perform data extraction and analysis of all the rotator cuff studies identified through the literature searches. These efforts led to a description and categorization of instruments and other measures used to assess rotator cuff disorders, which were then used as a basis for developing the core outcome measures. The project was presented at two MCubed Symposia, once as an oral presentation and once as a poster.

\section{Librarian Participation Significance}

By partnering on the project, the Informationist was in a position to demonstrate the importance of librarian involvement in systematic review projects to a nonlibrarian, research audience. As literature searches form the basis of systematic reviews, they are an ideal output for demonstrating the value of librarian contributions to research. In fact, research shows that librarian involvement in such projects improves search strategy reporting, ${ }^{11}$ an essential component of systematic review publications that adhere to accepted reporting standards. Furthermore, the work generally performed by librarians in systematic reviews is often unreported, ${ }^{12}$ despite being significant and often worthy of authorship or published acknowledgement. In this project, the Informationist was accepted as a fully integrated member of the team, perhaps in part because of the funding tied to his efforts. Regardless, being present at strategic meetings, articulating the importance of search processes and accepted standards, and contributing to methodological discussions about the project help redefine librarian roles in research as one of a partner more than one of support.

\section{Using the Digital to Read Literary Texts in Context}

\section{Cube Discovery Process}

This project grew out of a series of conversations among the English Language and Literature Librarian, the Data Visualization Librarian, and a faculty member in English who wanted to explore the possibilities of using digital approaches to studying regional literature in its periodical context. Both the English Language and Literature Librarian and the faculty member in English work in the field of American periodicals studies, and their scholarly interests overlapped in this project. While many digital humanities 
projects draw on large corpora of texts to perform what Franco Moretti has termed "distant reading," 13 this project explored the kinds of data that could be derived from close readings of texts in an entire run of a periodical.

\section{Librarian Role in Cube}

While this project reflected the faculty member's scholarly interests in American periodicals, the specific object of study emerged from a book manuscript project that the English Language and Literature Librarian was working on related to analyzing regional literary fiction in the context of early twentieth-century California magazines. For this reason, the English Literature Librarian was able to actively shape the research goals of the project. Likewise, the methodology for data collection was one that the Data Visualization Librarian was working to develop for other researchers to adapt. There has been a growing interest, especially in the humanities, for methods and technology to aid in rigorous, controlled, and collaborative data creation, and this project was an opportunity to explore potential approaches. Thus, both librarians played key roles in determining and contributing to the project's research agenda.

In addition to shaping the project's research agenda, the librarians played a key role in determining the workflow for accomplishing this project, both as a research project at scale and through collaboration with undergraduates, graduate students, and faculty. Whereas collaboration is relatively rare in the humanities, librarians bring considerable skills in collaboration and project management.

\section{Work Accomplished from Funding}

As determined by MCubed, the majority of the grant funds were spent on undergraduate and graduate researchers who worked as a team on the project. The collaborators, along with a team of undergraduate and graduate student researchers, identified data points to be collected based on common themes and elements in the magazine. A graduate student in Information Science built a web-based tool for data entry, validation, and storage. In addition to bibliographic information, the data points included thematic, economic, cultural, and geographic information. For example, because the magazine focused on the ethnography of the Southwest, the research team recorded identity groups mentioned, activities, and geographic locations. Although the data collection phase took the bulk of the funded project time and in fact has only recently been completed, the research team has already begun sorting, sifting, and visualizing it to look for patterns and networks. The work was presented at two MCubed symposia. Preliminary analyses of the data have revealed unexpected patterns in authorship in the magazine, such as the unusually high number of contributions by female authors, and the project managers are currently outlining additional grant proposals to fund research that builds on the initial dataset.

\section{Librarian Participation Significance}

One of the most important lessons learned in this project was the crucial mentoring role that librarians can and do play in graduate education, especially in the field of digital scholarship. Although the project leaders had initially intended to hire only a few graduate students to oversee a team of undergraduates, the interview process revealed an eagerness among graduate students to become involved in digital projects. As a result of hiring an interdisciplinary team of advanced undergraduates and graduate students, the project benefited greatly from becoming a collaborative team effort. This insight into the key role of librarians in mentoring graduate students in digital projects was the focus of a recent coauthored chapter published by the Librarian for English Language and Literature and the Data Visualization Librarian. ${ }^{14}$ 
Another significant lesson learned in this project was the enormous investment of resources required by institutions, including libraries, interested in supporting digital scholarship. Not only are digital projects necessarily highly collaborative, but they also require financial resources and technological expertise far beyond what is available to the individual researcher who is simply curious about the digital humanities. The project allowed the librarians involved to develop methodologies for data collection in the humanities that will be beneficial to other researchers on campus. While not all researchers have grant money to invest in staffed projects, librarians can nevertheless advance digital scholarship by contributing subject expertise, as well as project and data management advice, and helping researchers make connections with potential collaborators.

\section{Discussion}

Librarians are often considered support personnel rather than primary collaborators; but the projects discussed in this article demonstrate that librarians can and should be primary collaborators, as they can play valuable roles in research projects. Being a funding partner is one method for solidifying librarians as research partners, although obtaining funding is not an easy task for librarians. The authors of this article were able to provide a limited amount of funding and their expertise to three unique projects, showing the range and value of library engagement.

A clearly identifiable theme across all these projects was that each benefited from librarian involvement. Mentorship, expert searching, and project management provided by librarians were key to the success of the projects discussed in this article. Librarians in academic settings provide students with real-world experiences and opportunities to grow. They train students to use good communication skills, ideal research techniques, suggested data management practices, and more; as a result, librarians are natural mentors. As skilled searchers, librarians are often partners for projects that involve searching, such as systematic reviews. Having a librarian on the team ensures an accurate, efficient, and comprehensive search. Many librarians seek and deserve authorship for their expert searching role because of the necessary time commitment and the significant intellectual and methodological contributions they can make to a project. Regardless of the project, librarians are often equipped to take on more than searching responsibilities, instead providing valuable input in project planning and discussion. These projects demonstrate how librarians' project management skills ensure successful outcomes.

The interdisciplinary nature of these projects provided a significant benefit for librarians. The authors established collaborations that otherwise might not have been formed and strengthened existing connections. The library became an equal funding partner, which was meaningful given the importance of grant funding for the authors' research partners. In addition, the projects and librarian roles discussed in this article show the variety of ways in which librarians can get involved. Collaborators learned that librarian engagement leads to positive outcomes, encouraging them to tell their colleagues and collaborate with librarians in the future. In addition, MCubed provided an invaluable experience for librarians to be involved in long-term projects, which allowed the authors to develop methods and ways of working that were transferable at different scales to shorter-term projects.

Working in an academic library, a lot of value is placed on sharing work both within and outside the library profession. The projects and the librarian roles discussed in this article have led to a variety of opportunities for disseminating and sharing work. UM held an annual MCubed symposium in which each of the cubes presented a poster, sharing their work with the rest of the UM community. These symposia were open 
for anyone to attend and highlighted the work accomplished. Librarians worked with the students to create these posters, were either authors themselves or mentioned as primary collaborators, and helped present the posters at the symposia. A book chapter about librarian involvement in tranSMART discusses the project management and mentorship role played in the tranSMART MCubed project. ${ }^{15}$ This was significant since it stressed the value of librarians embracing such a role. The authors of this article were also members of a panel on campus showcasing librarian involvement in these projects. The panel provided an opportunity to express the value of librarians as collaborators, in hopes of encouraging more librarians to pursue such opportunities.

Although the library's involvement in MCubed was a success, these projects were not without their challenges. The interdisciplinary nature of the projects was in many ways a strength, but this also led to there being a variety of stakeholders, with differing interests, for each project. Maintaining good communication among all stakeholders was not easy and at times created frustrating bottlenecks for information gathering and decision making. Another challenge was the timeline, as all librarians found that it took time to get their projects started. This meant that, although the funds for hiring students were available, it was a while before the projects were at the hiring point. As a result, a longer funding period or a staggering between the notification of getting funding and when the funding became available would have been extremely useful.

The next cycle of MCubed will be from 2015 through 2017, and, due to the library's success in the first cycle, the library will be participating again. Given the interest in including librarians in cubes, for the next cycle the library is funding more tokens, but most tokens will be worth $\$ 5,000$ instead of $\$ 20,000$. As a result, a larger number of projects that include librarians can be funded. The more projects that involve librarians, the more integral librarians become in the research process as partners and collaborators.

\section{Conclusion}

MCubed provided the authors a unique opportunity to be part of collaborative research teams at their institution. As evidenced by this paper, the range of research projects that benefited from librarian collaborators is large and encompassed all disciplines. In addition, librarians played a variety of roles, ranging from project development and conducting essential literature searches to providing mentorship and project management. Librarians should seek out opportunities to be full collaborators, whether via large grants or smaller funding opportunities, such as UM's MCubed initiative. As more researchers recognize and understand the value of library participation, it will become the rule rather than the exception for librarians to be viewed as primary collaborators instead of support personnel.

\section{Acknowledgments}

The authors would like to thank all the students, faculty, and staff that put effort toward these projects to make them successful. We would like to thank Paul Trombley for his help designing the figure presented in this article. We would also like to thank the University of Michigan's MCubed initiative for funding support.

\section{Notes}

1. Jake Carlson and Ruth Kneale, "Embedded Librarianship in the Research Context," College \& Research Libraries News 72, no. 3 (2011): 167-70; Amalia Monroe-Gulick, Megan S. O'Brien, and Glen White, "Librarians as Partners: Moving from Research Supporters to Research Partners," in Imagine, Innovate, Inspire: The Proceedings of the ACRL 2013 Conference, edited by Dawn M. Mueller (Chicago: Association of College and Research Libraries, 2013): 382-84; Megan Oakleaf, The Value 
of Academic Libraries: A Comprehensive Research Review and Report (Chicago: Association of College \& Research Libraries, 2010): 47-49.

2. Sally A. Gore, Judith M. Nordberg, Lisa A. Palmer, and Mary E. Plorun, "Trends in Health Sciences Library and Information Science Research: An Analysis of Research Publications in the Bulletin of the Medical Library Association and Journal of the Medical Library Association from 1991 to 2007," Journal of Medical Library Association 97 (2009): 203-11.

3. Elizabeth M. Smigielski, Melissa A. Laning, and Caroline M. Daniels, "Funding, Time, and Mentoring: A Study of Research and Publication Support Practices of ARL Member Libraries," Journal of Library Administration 54 (2014): 261-76.

4. Dangzhi Zhao, "Characteristics and Impact of Grant-Funded Research: A Case Study of the Library and Information Science Field," Scientometrics 84 (2010): 293-306.

5. Amalia Monroe-Gulick, M.S. O'Brien, and G. White, "Librarians as Partners," 383.

6. Regents of the University of Michigan, "About MCubed," (2015), available online at http:// mcubed.umich.edu/about [accessed 24 August 2015].

7. Mark Burns et al., "MCubed: Michigan's Revolutionary Seed Funding Program," MCubed Information Session Presentation (2015), available online at http://mcubed.umich.edu/sites/default/ files/files/WebVersionMCubedInfoSessionsMay2015.pdf [accessed 24 August 2015].

8. Brian Athey, Michael Braxenthaler, Magali Haas, and Yike Guo, "tranSMART: An Open Source and Community-Driven Informatics and Data Sharing Platform for Clinical and Translational Research," AMIA Joint Summits on Translational Science Proceedings AMIA Summit on Translational Science (2013), 6-8; Elisabeth Scheufele et al., "tranSMART: An Open Source Knowledge Management and High Content Data Analytics Platform," AMIA Joint Summits on Translational Science Proceedings AMIA Summit on Translational Science (2014), 96-101.

9. To view the tranSMART tutorials, see the YouTube channel, available online at www. youtube.com/playlist?list=PLv0yMFogDiDhBc_nOoHkCwCGY_Fu8hK6D [accessed 24 August 2015].

10. At THL, librarians have the title "Informationist."

11. Melissa L. Rethlefsen, Ann M. Farrell, Leah C. Osterhaus Trzasko, and Tara J. Brigham, "Librarian Co-Authors Correlated with Higher Quality Reported Search Strategies in General Internal Medicine Systematic Reviews," Journal of Clinical Epidemiology 68, no. 6 (2015): 617-26.

12. Jonathan B. Koffel, "Use of Recommended Search Strategies in Systematic Reviews and the Impact of Librarian Involvement: A Cross-Sectional Survey of Recent Authors," PLoS One 10, no. 5 (2015): 1-13.

13. Franco Moretti, Distant Reading (London: Verso, 2013).

14. Sigrid A. Cordell, Alexa Pearce, Melissa Gomis, and Justin Joque, "Filling the Gap: Digital Scholarship, Graduate Students, and the Role of the Subject Specialist," in Supporting Digital Humanities for Knowledge Acquisition in Modern Libraries, eds. Kathleen Sacco, Scott Richmond, Sara Parme, and Kerrie Fergen Wilkes (Hershey, Penn.: IGI Global, 2015), 67-85.

15. Marci D. Brandenburg, "Librarian Involvement in tranSMART, a Translational Biomedical Research Platform," in Translating Expertise: Librarian Roles in Translational Research, ed. Marisa Conte (Lanham, Md.: Rowan and Littlefield, 2016) 27-42. 